Dossiê: Diálogos do Sul

\title{
Sociologias do Sul \\ Ensaio bibliográfico sobre limites e perspectivas de um campo emergente
}

\section{Sociologies of the South}

Bibliographical essay on limits and perspectives of an emerging field

\author{
Marcelo C. Rosa*
}

Resumo: Este artigo discute as recentes publicações na área de ciências sociais que buscam apontar a noção de Sul com alternativa teórica, metodológica ou epistemológica aos efeitos coloniais nesta área do conhecimento. Por meio de uma revisão crítica dos argumentos de Boaventura de Sousa Santos, Raewyn Connell e Jean e John Comaroff em suas obras mais recentes, procura apontar as principais fragilidades destas perspectivas e possíveis caminhos alternativos à produção acadêmica fora da euro-américa.

Palavras-chave: Sociologias do Sul. Teoria social. Modernidade. Pensamento social. Sociologias alternativas.

Abstract: This paper reviews the recent literature in the field of social sciences in which the term "South" is regarded as a theoretical, methodological or epistemological alternative to the colonial effects of our disciplines. Analysing the books of Boaventura de Sousa Santos, Reawyn Connell and Jean and John Comaroff it seeks to point out some of their fragilities and possible alternative paths for a sociology beyond the EuroAmerican tradition.

Keywords: Southern sociology. Social theory. Modernity. Social thought. Alternative sociology.

\section{Introdução}

Não é novidade o desconforto de uma parcela significativa dos cientistas sociais em nossos países com a forma pela qual nossas disciplinas

* Doutor em Sociologia pelo Iuperj (Rio de Janeiro), professor no departamento de Sociologia da Universidade de Brasília, DF, bolsista de produtividade em pesquisa do CNPq $<$ marcelocrosa@ gmail.com>.

\begin{tabular}{|c|c|c|c|c|c|}
\hline Civitas & Porto Alegre & v. 14 & n. 1 & p. $43-65$ & jan.-abr. 2014 \\
\hline
\end{tabular}


construíram uma narrativa mestra ao se apropriarem das teorias sociológicas euro-americanas para dar sentido à ideia de sociedade em que vivemos. Nas décadas de 1950 e 1960, obras de Aimé Césaire e Franz Fanon, dentre outras, já haviam criticado seus impactos nas subjetividades dos sujeitos colonizados, enquanto as teorias da dependência afrontavam diretamente os modelos desenvolvimentistas de seu tempo, impondo-se, mesmo que topicamente, como alternativa interpretativa para a questão da desigualdade global.

Ao longo das últimas duas décadas, novos movimentos teóricos evocados em rótulos tão diversos como pós-coloniais (Chakarbarty, 2000) ou decoloniais (Mignolo, 2009), atentos a modernidades múltiplas (Eisenstadt, 2000) ou a distintas fases da modernidade (Domingues, 2009) retomaram aquelas reações pioneiras vis-à-vis as experiências africanas, asiáticas e ameríndias contemporâneas. A própria Associação Internacional de Sociologia organizou recentemente dois livros que trazem à tona um profundo debate em curso sobre este tema (Burawoy, Chang e Hsieh, 2010; e Patel, 2010). É preciso admitir, no entanto, que os movimentos teóricos do passado e as novas tendências críticas e analíticas mencionadas têm hoje um legado diminuto nos debates legítimos não somente nos círculos acadêmicos da sociologia euro-americana como também naqueles localizados em países onde essas abordagens foram produzidas, como o apontam Go (2013) e Alatas (2006).

A este conjunto de debates, cujas principais linhas já estão razoavelmente traçadas -a ponto de serem reconhecidos nas disputas internas das ciências sociais-, se soma agora uma nova alternativa, organizada em torno do rótulo teorias do Sul. Mesmo considerando esse novo movimento teórico parte constituinte do grande conjunto acima mencionado, precisamos reconhecer que há aqui a introdução de uma nova ferramenta (poderíamos pensar também em lente) que ainda não havia sido trazida para o centro da disputa geopolítica de nossas disciplinas: $o$ Sul.

Se levarmos em consideração tão somente os últimos sete anos, é possível destacar três contribuições centrais na constituição deste desafio específico ao corpus conceitual anteriormente constituído: o trabalho desenvolvido por Boaventura de Sousa Santos sobre as epistemologias do Sul, a coleção de artigos de Raewyn Connell sobre as sociologias de países do Sul e, por último, o recente trabalho dos antropólogos Jean Comaroff e John Comaroff sobre teorias do Sul. Diferente dos demais textos citados acima, somente estes trabalham com o termo Sul e esse é o sentido de tê-los escolhido neste artigo.

Neste texto procurarei, por meio de uma estratégia próxima ao que em inglês se chama de literature review, discutir as formas como o Sul tem 
sido trazido para o centro das disputas teóricas das ciências sociais nestas publicações. Usando a noção de economie de la grandeur cunhada por Boltanski e Thévenot (1991) e por Boltanski (2000), descrevo as grandezas ou virtudes que aparecem associadas ao Sul em cada obra e como a partir delas esses autores delineiam o universo de disputas teóricas em seus livros, a fim de torná-los contribuições legítimas ao debate sociológico contemporâneo.

Ao invés de resenhar as obras em si, exploro as formas e os momentos nos quais o Sul é nelas invocado com potencial heurístico para modificar o programa das ciências sociais de acordo com cada autor. Para este exercício focalizado explorarei algumas questões específicas, que considero problemáticas nessas obras, a fim de tornar mais complexo o debate sobre os sentidos e apropriações do Sul. A primeira delas diz respeito à opção de Boaventura de Sousa Santos de demarcar as "epistemologias do Sul" com termos como tradição e formas não científicas. A segunda, é uma crítica aos Comaroff que, ao tentarem promover as teorias do Sul, acabam por reificar o dualismo clássico das ciências sociais tradicionais entre teorias teóricas do norte e teorias práticas no Sul. E a última indica uma falta de preocupação de Connell com os processos internos de colonização das ciências sociais por narrativas euro-americanas, quando esta autora defende as teorias sociais produzidas no Sul como potencialmente alternativas.

\section{O Sul como epistemologia e esperança}

O cientista social português Boaventura de Sousa Santos, em seus escritos desde a década de 1990, vem procurando questionar a universalidade do projeto epistemológico das ciências ocidentais, para isso combinando as descobertas da "ciência social" com outras formas de conhecimento. Como tem afirmado em suas obras, ele busca desafiar a superioridade imposta pelo conhecimento científico do norte em relação a outras formas de conhecimento que ainda sobreviveriam no Sul, erigindo uma distância intransponível sob a forma de um modo de pensamento abissal.

O livro Epistemologias do Sul, de 2009 e editado com Maria Paula Meneses, é uma coletânea que reúne perspectivas que seriam parte de um mesmo esforço teórico: romper o modelo colonial de produção do conhecimento. Nele são presentados textos que cobrem desde a literatura pós-colonial africana, passando pelos estudos subalternos indianos e os autores decoloniais latinoamericanos. Para preservar a comparação com os textos autorais de Connell e dos Comaroff não analisarei neste momento o conjunto do livro, mas as contribuições de Sousa Santos com Maria Paula Meneses (introdução) e dele 
próprio (capítulo 1). Em outras palavras, me dedico aos escritos onde a noção de $S u l$ é explicitamente associada a formas alternativas de conhecimento.

Logo nas primeiras páginas da introdução, os autores definem seu objetivo como uma crítica da perspectiva colonial do conhecimento científico, compreendido como uma representação do ocidente que combina processos de secularização e a expansão capitalista global. O Sul, nas palavras de Santos e Meneses (2009, p. 12), "é aqui concebido metaforicamente como um campo de desafios epistemológicos que tenta reparar os danos e impactos historicamente causados pelo capitalismo na sua relação colonial com o mundo" (grifos meus).

Para ambos "as epistemologias do Sul são o conjunto de intervenções epistemológicas que denunciam essa supressão dos saberes dos povos e nações colonizadas, valorizam os saberes que resistiram com êxito e investigam as condições de um diálogo horizontal entre conhecimentos" (Santos e Meneses, 2009, p. 13). Nesse sentido, o Sul não corresponde a uma unidade geográfica, mas a uma forma epistemológica específica que se definiria por sua relação negativa e reparadora com o capitalismo colonial.

Para Santos, a modernidade ocidental e sua forma científica de ver o mundo se transformaram em instrumento de dominação ao excluírem, pela força, a possibilidade da coexistência de outras formas de conhecimento. Para a colonização das mentalidades locais fora da Europa foi lançado mão do que Enrique Dussel, em seu capítulo no mesmo livro, chama de retórica da esterilização e da ausência de formas razoáveis de conhecimento. O grande oponente do Sul é, portanto, o colonialismo como expressão do capitalismo e de sua forma de conhecimento instrumental.

O problema, segundo Santos e Meneses, não seria necessariamente a existência inexorável da colonização e de sua narrativa mestra, a saber, o pensamento científico. A questão central residiria no fato de que esses processos não admitiriam aquilo que Johannes Fabian (2000[1983]) e, posteriormente, Walter Mignolo (2000) chamaram de co-presença, coexistência ou coetaneidade (coelvalness) de outras formas sociais e de seus saberes. Para a ordem-colonial-global-capitalista, formas e fórmulas societais espalhadas pelo mundo têm sido colocadas à margem ou simplesmente não reconhecidas como experiência significante.

$\mathrm{Na}$ impossibilidade de simplesmente excluir a colonização e as consequências da modernidade de suas vidas cotidianas colonizadas, para os autores, os povos do $\mathrm{Sul}$ teriam se adaptado e criado modernidades alternativas. Outra das saídas peculiares aos povos do Sul, apontadas pelos autores, seria a instituição de um "cosmopolitismo subalterno", "significando tolerância, 
patriotismo, cidadania global, comunidade global de seres humanos, culturas globais etc." (Santos, 2009, p. 41). ${ }^{1}$ A base deste cosmopolitismo seriam as diferentes temporalidades na quais "as experiências subalternas do Sul global têm sido forçadas a responder tanto à curta duração das necessidades imediatas de sobrevivência como à longa duração do capitalismo e do colonialismo" (Santos, 2009, p. 50).

A recente emergência dos representantes indígenas e de suas formas próprias de organização nos fóruns internacionais de esquerda (o palco fundamental analisado pelo autor é o Fórum Social Mundial) demostraria as possibilidades de um hibridismo entre ocidente e não-ocidente, em que movimentos clássicos de esquerda se aliam a comunidades negras, indígenas, sem-terras e feministas.

Para o autor, a despeito desses encontros criarem novas relações políticas, "esta diversidade continua desprovida de uma epistemologia adequada" (Santos, 2009, p. 45) que permita um livre trânsito de ideias entre grupos tão diferentes. Seu projeto acadêmico consiste, portanto, em construir uma epistemologia que dê conta desta diversidade e que permita unir realidades assimétricas.

Aqui vejo um ponto complicado na retórica de Boaventura de Sousa Santos, pois ao mesmo tempo em que exalta a pluralidade de formas de conhecimentos e suas incompletudes, o pensador português parece angustiado em fornecer uma fórmula única para seu convívio.

Não seria uma epistemologia convergente, mesmo que provisória, justamente o mesmo que o autor critica quando se refere ao pensamento científico? Ele provavelmente acha que não, pois acredita no universalismo cosmopolita, como vimos acima. Deste tipo de pergunta Boaventura de Sousa Santos se esquiva com a seguinte resposta: "precisamos, para seguir em frente, de uma epistemologia geral residual ou negativa: uma epistemologia geral da impossibilidade geral" (Santos, 2009, p. 46).

Ao que parece, para se desconstruir uma forma hegemônica seria preciso construir outra, agora povoada com a imaginação também dos colonizados. De meu ponto de vista, este tipo de saída elíptica não nos ajuda a superar o colonialismo epistemológico, pois mantém intacto o dilema entre ou a imposição de uma epistemologia (geral e que dê conta das diversidades) ou a aceitação de várias epistemologias (que não necessariamente se comunicam

Para debates recentes entre autores do Norte e do Sul sociológico sobre a noção de cosmopolitismo e seus dilemas, consultar as últimas edições da Newsletter da International Sociologial Association (ISA) "Global Dialogue" <www.isa-sociology.org/global-dialogue/>. 
ou querem se comunicar) espalhadas pelo mundo colonizado em condições, durações e com consequências tão diferentes.

Santos parece reconhecer (junto aos demais autores que compõem o livro) que a existência de epistemologias diversas não implica que elas necessariamente se comuniquem. Sua proposta, como vimos, é promover, por meio de um diálogo das diferenças classificado como uma ecologia dos saberes, um ponto em comum não-hierárquico entre o conhecimento científico (do Norte) e o tradicional (do $S u l$ ). É importante notar que por mais que o $S u l$ seja concebido como o encontro entre a ciência e outras formas locais, são suas qualidades não científicas - outros saberes- que recebem a atenção do autor.

Mas, novamente, não seria a busca desse ponto em comum justamente o motor do próprio projeto "liberal-democrático-ocidental"? Não seria essa retórica mais uma concessão da diversidade do Sul às necessidades simplificadoras do Norte? Como colocar em um mesmo escopo epistemologias feministas e pós-coloniais, o Movimento dos Sem-Terra, quilombolas e indígenas (exemplos usados pelo autor) sem reincidir em uma réplica do que sempre fez a ciência social tradicional. Em minha crítica esta união ecumênica constitui uma espécie de Outro do Norte e não uma composição sustentada em especificidades próprias para além da vaga noção de tradicional usada ao longo das páginas.

Para demonstrar as virtudes e as diferenças das sociedades dos Sul, o próprio autor explica quais seriam os locais dessa nova epistemologia: "sociedades periféricas do sistema mundial moderno, onde a crença na ciência moderna é mais tênue, onde é mais visível a vinculação da ciência moderna aos desígnios da dominação colonial e imperial, e onde outros conhecimentos não científicos e não-ocidentais prevalecem nas práticas cotidianas das populações (Santos, 2009, p. 47).

Se não é difícil para os leitores de Santos perceberem os efeitos perversos das epistemologias coloniais, é quase impossível reconhecer no seu texto quais conhecimentos seriam estes que estariam do "outro lado da linha". Dizer que são "populares, leigos, plebeus, camponeses e indígenas" (Santos, 2009, p. 25 ), termos exemplarmente cunhados pela epistemologia do norte, como o faz o autor, não seria justamente tomá-los pelas categorias que o colonizadorcapitalista-globalizado criou para acomodá-los em uma ordem hierárquica de formas de conhecimento?

\section{O Sul como a vanguarda do caos}

Seguindo a mesma forma editorial dos demais textos aqui analisados, o recente livro do casal sul-africano, radicado nos Estados Unidos, Jean and 
John Comaroff, traz igualmente uma longa introdução chamada Teoria desde o Sul destinada a amarrar uma série de artigos já conhecidos do público (além da introdução ao livro, apenas um capítulo é inédito). Esta introdução servirá de base para nossa análise, pois somente ali a questão do Sul é satisfatoriamente formulada.

Os Comaroff começam seu ensaio abraçando a tese de que, por décadas, nossas sociedades foram tratadas como apenas exóticas, paroquiais e palco de tradições antiquadas (2011, p. 1). Outro tema conhecido, abordado pelo texto, é o fato de o $\mathrm{Sul}$ ter sido tradicionalmente um produtor de matéria-prima para as teorias sociais elaboradas no norte. Na sua visão, no entanto, este quadro estaria prestes a se alterar na medida em que certos processos sociais do Sul começam a se espalhar pelo globo.

A aposta dos autores é subverter o que chamam de estruturas epistemológicas (e aqui temos novamente a vaga, mas forte palavra usada por Santos) desta hierarquia, partindo da hipótese de que neste momento histórico, o Sul global é quem deve fornecer os insights para se compreender o resto do mundo.

Tais insights aparecem em termos como invenções, acomodações e híbridos usados em profusão no texto (Comaroff e Comaroff, 2011, p. 6). No Sul, sob diferentes contextos coloniais, têm sido criadas formas de vida doméstica e urbana, de "proletarização camponesa", de "cosmopolitismos deslocados forjados em espaços que estão entre o prometido e a privação, entre a exclusão e a obliteração" e que serviriam para estabelecer suas próprias contemporaneidades e modernidades (Comaroff e Comaroff, 2011, p. 7). Apesar da insistência em descrever os processos sociais do Sul pela sua criatividade em lidar, em situações de escassez, com as questões mestras da vida do Norte, os autores declaram que não desejam apenas reverter o processo, que ao cabo manteria a mesma topografia das análises críticas tradicionais.

Para os Comaroff, a modernidade do Sul não é apenas uma derivação ou uma cópia falsificada daquela vivida na Europa. Ela precisa ser entendida pelo seu relacionamento com o Norte, mas também com o Sul, com suas próprias experiências e dilemas. Como veremos adiante, são esses dilemas e suas soluções que hoje trariam vantagens competitivas ao $\mathrm{Sul}$, em um quadro de crise na Euro-américa.

Em um nítido esforço de salvaguardar a modernidade, a modernização e seu telos teórico/normativo são apresentados como fatores que tenderam a hierarquizar sociedades e a estabelecer noções de tempo e de espaço discriminatórias e unilineares. Já a modernidade - em certo ponto descrita usando palavras de David Harvey - é vista como uma visão progressiva da 
história ou como uma ideologia do melhoramento por meio da acumulação de conhecimento e capacidades técnicas (Comaroff e Comaroff, 2011, p. 9). Como conceito e como prática seria menos nociva, porque se inscreve e se modifica de acordo com contextos específicos.

Na modernidade do Sul, a dialética "capitalismo-e-modernidade" teria gerado novos padrões "radicais" de relação entre capital e trabalho. Como diz a autora em uma recente entrevista sobre o livro para uma revista brasileira:

E, dado o estado das cidades por toda parte, essas comunidades (e percebo que não são todas iguais; que variam em condições de vida e possibilidade) repentinamente parecem muito avant garde. Elas, assim como a corrupção, não podem mais ser vistas meramente como desvios de um plano mais racional, como aberrações temporárias ou escândalos do terceiro mundo (Comaroff, 2011, p. 480).

Este tema serve de preâmbulo e leva diretamente a outra questão polêmica do livro, presente no seu subtítulo, que é a evolução da Euro-américa para a África. Os autores deixam claro que se trata de uma expressão provocativa e não de uma assertiva sobre o fato de estar havendo uma involução na história do Norte. Por aceitar, mesmo que parcialmente as noções de modernidades múltiplas, os autores concebem que a vida no $S u l$ acontece em paralelo e em relação ao Norte. Se por muitas décadas acreditávamos que o Sul evoluiria para o Norte, parece que agora é o Norte que tomará ares de $S u l$ em diversos sentidos. A questão que não está suficientemente clara no texto é saber se eles creem que isto se dará porque há um diálogo e um aprendizado do Norte com o Sul ou se o caminho tomado pelo norte (a crise) é o caminho inexorável já experimentado pelo Sul.

Temos, nesse ponto, outra relação que os autores não hesitariam em chamar de dialética entre (1) modernidades múltiplas com temporalidades paralelas e (2) uma modernidade sui generis que envolve o Sul e o Norte: a modernidade neoliberal.

É no espaço de debate deste tema que, a meu ver, os autores tentam, para agradar aos vários possíveis leitores, juntar a ideia de Sul com a narrativa recente sobre os efeitos do neoliberalismo. Para eles, os eventos do Sul seriam a epítome do capitalismo em seu estágio atual neoliberal e por isso o Norte estaria cada vez mais parecido com o Sul.

Como em outros textos, o tom pessimista dos autores sobre a África sua experiência de pesquisa se concentra na África do Sul e em Botswana-e que se espalha sobre o $S u l$ de todo o mundo não é, no meu entender, diferente de outras ênfases possíveis de serem encontradas em outros textos clássicos. 
Aqui temos a insistência em afirmar, com um ar de generalidade agradável aos financiadores e think-tankers euro-americanos, que os governos da África estão baseados em uma "patronagem cleptocrática e que a falta de estados liberais democráticos não tem sido capazes de controlar aqui as forças de mercado" (Comaroff e Comaroff, 2011, p. 16). Ou, ainda, em declarar que se tratam de ambientes nos quais a "força da lei, dos contratos de trabalho e da ética da sociedade civil, são, no melhor dos casos, desiguais" (Comaroff e Comaroff, 2011, p. 19). Tais argumentos em meu entendimento apenas reforçam o estigma de que o Sul é um objeto podre na mão do capital do Norte.

Para a surpresa dos críticos que acham que já entenderam as posições defendidas no texto, poucas páginas adiante temos mais uma frase definitiva: "And not all is darkness" (nem tudo são trevas) (Comaroff e Comaroff, 2011, p. 18). Para os Comaroff, a África é também fonte de respostas inventivas às contingências do tempo presente. Respostas que são guiadas por uma mistura volátil de necessidade, possibilidade, desregulação e de compressão do tempoespaço (Comaroff e Comaroff, 2011, p. 18). Ao ler o livro, um cientista social bourdiano, por exemplo, não teria dúvidas em afirmar que, de acordo com os autores, movidos pelas pressões estruturais, as populações do Sul desenvolveram um consciência prática para lidar com a incerteza. São modos imaginativos de sobrevivência. Enquanto o Norte vive/age, o Sul sobrevive/ reage, e mesmo que sem muita consciência pode até mesmo ter inventado algumas saídas próprias para a crise. Valendo-me do mesmo argumento utilizado por Ortner (2001), em sua crítica a outra obra dos Comaroff, me parece que não há espaço em sua análise para uma agência que não seja a do capital e dos capitalistas.

Este tipo de retórica talvez tenha efeito aos olhos das ciências sociais e da mídia de esquerda euro-americana que continua a ver o Sul como um lugar de ausências, como o coração das trevas (parafraseando aqui o uso de Francis Nyamnjoh, 2012, para o clássico de Joseph Conrad Heart of darkness). O argumento desses dois antropólogos é, no entanto, devastador para aqueles que têm buscado construir as agências e as convivialidades das formas de conhecimento no Sul (Borges, 2009; Nyamnjoh, 2012).

O clima acalorado e retórico quase nos faz esquecer que o livro fala de teorias do Sul. Tenazes, os autores nos levam então para o universo do que consideram uma produção teórica do Sul. É entre os Tswana, de seu texto de 1997, e sua noção de pessoa multifacetada e cultuada desenvolvida na relação colonial que temos um esboço dos caminhos futuros do Sul.

De meu ponto vista, o dilema que se coloca, diante das afirmações dos autores sobre o caráter especular ou mimético dos processos experimentados 
no Sul e no Norte, seria: como compreender que esses novos processos constituam uma teoria do Sul? Para os Comaroff, teorias não significam o mesmo que as grandes teorias da tradição modernista. Não seria um recurso à abstração ou a uma antropologia filosófica. Eles clamam por uma "teoria aterrada" (grounded theory) que seja historicamente contextualizada (embora pareçam aceitar tranquilamente uma única ideia de história capitalista), que seja guiada pelos problemas da produção dos fatos estudados. Um meio termo entre o concreto e o conceito, entre o épico e o cotidiano, o significativo e o material. Em suas palavras: "nossa predileção é por uma teoria que não seja uma metanarrativa abrangente, nem 'micro-socioeconomicamente' míope ou local" (2011, p. 48). Enfim, uma teoria que busca "explicar" os fenômenos pela relação entre as grandes determinações e as condições contingentes e próximas.

A noção de teoria é aqui interessantemente modificada e passa a admitir como teóricas as soluções práticas encontradas nesses países. Pela sua própria forma de apresentação - pelo seu método - torna-se difícil apostar no potencial teórico-epistemológico das situações sociais descritas pelos autores. A construção de uma narrativa "aterrada" toma no livro a forma de achados de pesquisa dos autores em relação às grandes teorias euro-americanas, repetindo o modelo clássico que eles próprios criticam. Ao cabo, o livro acentua a ideia de que no Norte se constroem grandes teorias e no $S u l$ teríamos teorias aterradas - que dialogariam com as primeiras. Entretanto, poderíamos nos perguntar se esse aterramento não seria justamente aquilo que os autores chamam no começo do livro de produção de dados para as teorias do norte? Não seriam a práticas do Sul, as fontes para a generalização no Norte?

Apesar do desejo legítimo, parece que o problema dos Comaroff reside em sua dependência de conceitos e formas narrativas constitutivas do pensamento colonial de esquerda. ${ }^{2}$ Eles acolhem, sem qualquer crítica, os dualismos típicos da sociologia e da antropologia (e. g. micros e macros).

Uma possível resposta está na própria definição do que eles chamam de Sul: "o rótulo evidencia uma relação, não uma coisa em si. É um artefato histórico, é um significante em uma gramática cujo conteúdo semiótico é determinado, ao longo do tempo, por processos materiais, políticos e culturais, produtos dialéticos de um mundo global em movimento" (2011, p. 47).

\footnotetext{
2 Grosfoguel (2012), um dos autores mais atuantes do pensamento decolonial, usa a expressão "esquerda branca" para descrever os intelectuais do Sul e do Norte que criticam o colonialismo, sem abrir mão das categorias europeias. Na África do Sul, é comum no meio dos movimentos sociais o uso da expressão "white liberals" para descrever sujeitos políticos bem intencionados que não conseguem se livrar de seus preconceitos eurocêntricos.
} 
O Sul global "ganha significados pela virtude não de seu conteúdo, mas de seu contexto" (2011, p. 45) na grande narrativa do capitalismo/colonialismo. Neste sentido, não há necessidade de uma revisão das narrativas históricas ou sociológicas como propuseram os textos subalternos, pós-coloniais ou decoloniais.

Já que o Norte, sem medo do trocadilho, continua a ser o norte das narrativas e processos sociais, mesmo em sua negatividade, os autores não hesitam em classificar, ironicamente, os eventos contemporâneos como “counter-evolution" (2011, p. 47). Poderíamos, por pura parcimônia, considerar como eles desejam que se isso seja uma ironia para lidar com a maneira evolucionista pelo qual termos como Terceiro Mundo foram cunhados no passado. Porém, se levarmos em conta a concepção relacional, segundo a qual Sul e Norte seriam de fato duas faces de um mesmo processo, cuja direção aponta agora para o que Norbert Elias chamaria de descivilização, não vejo outra saída senão pensar que para os Comaroff estamos de fato involuindo. Diante deste quadro, aqueles acostumados a viver no selvagem mundo da pobreza, da cleptocracia, do HIV, da magia, das favelas já estariam adaptados às situações adversas sendo, por isso, mais aptos para sobreviver às consequências destruidoras do neoliberalismo.

Assim como nos artigos replicados, que compõem o restante do livro, a recente incursão dos Comaroff aos desafios do Sul, em nenhum momento põe em xeque a leitura tradicional dos processos sociais vividos no Sul. Aliás, é a aceitação das piores faces destas sociedades que permite aos antropólogos estruturar suas teorias. Porque somos no $\mathrm{Sul}$, de fato, o que as ciências sociais tradicionais descreveram como sociedades defeituosas, temos condições de sobreviver no atual cenário do neoliberalismo globalizado. A única mudança é que por força da crise, agora esses defeitos (mesmo que não desejáveis) são úteis.

\section{O Sul e seu pensamento social}

Dentre os três trabalhos aqui analisados, o de Raewyn Connell pode ser considerado o único que busca apresentar sistematicamente "teorias endógenas" (Nyamnjoh, 2012; Mafeje, 2000), ou seja, alternativas teóricas produzidas fora da Euro-américa que equiparem Norte e $\mathrm{Sul}$ em termos de seus limites epistemológicos. Ao longo do livro de 2007, vemos em cada capítulo uma tentativa de engajamento com o pensamento social produzido em países do Sul. O Sul aqui tem locais bem definidos: a América Latina, a África, a Índia, o Irã e, supreendentemente para alguns, a Austrália. Sim, a Austrália (para quem não lembra denominada assim por significar literalmente "as terras 
do Sul"), aos olhos da autora, é sim um país do Sul que em termos sociológicos pode ser comparado àqueles acima relacionados, pois compartilha tanto dos efeitos colonialismo, quanto da periferização de sua produção sociológica - principalmente no reino da teoria. Ou seja, diferentemente dos Comaroff, para Connelll o Sul não pode ser definido por sua situação política e econômica, mas por sua posição intelectual (que não pode ser reduzidas aos termos acima).

Ao contrário dos livros mais recentes de Santos e Meneses e dos Comaroff, o livro de Connell já está há sete anos na estrada e por isso já recebeu muitas resenhas e críticas que também nos ajudam a compreender melhor seus impactos. Tais críticas, muitas delas feitas na própria Austrália e outras no Norte, em geral se atêm ao fato de o livro generalizar, para toda a sociologia clássica e contemporânea, problemas que seriam particulares de certo tipo de teoria colonial. Por outro lado, os maiores elogios a ele dedicados ressaltam o fato de a autora fazer um apanhado de teorias não hegemônicas e pouco acessíveis ao público clássico das ciências sociais.

Diferentemente dos demais, a discussão neste livro é intrinsecamente sociológica e os objetos de análise são teorias sociais produzidas por cientistas sociais radicados em situações coloniais. Ao contrário de Santos e Meneses, o livro não busca um diálogo com outras epistemologias (não científicas ou populares/práticas), mas sim com a própria sociologia de fora da Euroamérica. O argumento, sensível a muitos de nós radicados no Sul, é de que as sociologias produzidas fora da Europa e dos Estados Unidos (América do Norte no original) são tão marginalizadas quanto outras formas de conhecimento não ocidentais.

O uso do termo (do) Sul - Southern em inglês - significa "enfatizar relações - autoridade, exclusão e inclusão, hegemonia, parceria, apoio, apropriação - entre intelectuais e instituições na metrópole e na periferia do mundo" (Connell, 2007, p. IX). Mais explicitamente do que nos demais autores, Connell define o Sul por uma relação intelectual e não necessariamente cultural (como em Santos) ou econômica (como nos Comaroff).

Connell, quatro anos antes, apresenta o mesmo problema constatado pelos Comaroff, valendo-se do argumento do filósofo Paulin Hountondji (que tem um capítulo no livro de Santos e Meneses), de que enquanto a coleta e aplicação de dados acontecem nas colônias, as teorizações são privilégio das metrópoles. A autora estão se pergunta: quando as teorias sociais feitas no Sul - e como mostra o livro há muitas - poderão ser incorporadas pelos cientistas sociais do centro e, por paradoxal que seja, pelos próprios acadêmicos da periferia? 
Contrastando com o argumento de Santos e Meneses, Connell está interessada na forma pela qual sociedades "colonizadas e periféricas produzem pensamento social sobre o mundo moderno" (Connell, 2007, p. XII). ${ }^{3}$ Ou seja, ela não está a buscar os conteúdos não científicos ou da vida cotidiana para compará-los ao corpo de conhecimento teórico colonial.

No entanto, como ela mesma nos adverte, as ciências sociais periféricas não compartilham dos mesmos fundamentos entre si, contribuindo para que as tais formas próprias de fazer teoria sejam também diferentes. Nesse sentido, como afirmei anteriormente, as teorias em questão são mais "pensamento social", já que não se limitam a um escopo epistemológico específico, do que sociologia stricto senso.

Ao invés de aceitar a sociologia como ciência estabilizada (como fazem os Comaroff), Connell faz uma crítica profunda aos cânones da disciplina. Para ela, que interessantemente classifica Economia e sociedade e Da divisão do trabalho social como grand etnografias (no sentido de serem etnografias de larga escala sobre a vida social europeia), os trabalhos clássico e seu espírito comparado nunca admitiram os efeitos do colonialismo como variáveis de suas análises. Tal obliteração teria permitido aos clássicos cientistas sociais estabelecerem o papel do $\mathrm{Sul}$ em uma grande narrativa civilizacional/racional, sem enxergar o efeito de suas próprias ações teóricas. Em sua perspectiva, o universalismo pretendido pelos fundadores da sociologia somente pode existir pela sua ignorância e falta de diálogo com o universo intelectual dos países colonizados.

O mesmo poderia ser aplicado aos que chamamos de teóricos contemporâneos. Segundo Connell, a obra de Giddens, na ausência de engajamentos empíricos no Sul e no Norte, prefere alimentar seus leitores com situações imaginárias e com um esquema que define as sociedades em três tipos excludentes: tribal, dividida em classes e sociedade de classes (capitalismo). $\mathrm{Na}$ opinião de Connell, o autor britânico aposta na prevalência qualitativa das sociedades europeias por sua "precedência temporal" em relação às demais. A crítica é estendida para o alemão Ulrich Beck e sua expressão "The Brazilianization of Europe", que serve para evocar um futuro de fragmentação social horrenda, de violência e de egoísmo que deve ser evitada pela avançada Europa (Connell, 2007, p. 65).

Sobre a obra de Bourdieu pesam várias críticas, algumas delas voltadas para sua ideia de dominação masculina e para sua completa recusa em debater

\footnotetext{
No texto de Santos e Meneses há também a possibilidade de se pensar as epistemologias do Sul como formas de reação à modernidade. Apesar de este não ser o foco de sua construção.
} 
com os trabalhos da epistemologia feminista (campo de origem de Connell). Mais do que isso porém, chama a atenção de Connell o fato de Bourdieu não dialogar com intelectuais não europeus que faziam teorias sobre os mesmos lugares que ele. No caso da Argélia, é de estanhar a completa ausência de debate com Frantz Fanon, por exemplo. ${ }^{4}$ Bourdieu, assim como Giddens, coroaria o sujeito europeu como mais complexo e completo e, portanto, como o objeto de análise privilegiado por uma teoria que se interessa apenas pelo mundo moderno ou pelos caminhos para se chegar a ele. Neste enquadramento, seria na Europa, e não na Argélia que ele se revelaria de forma pura (afinal é de conhecimento geral que, ao menos desde Weber, os sociólogos preferem teorizar mais sobre os tipos puros ideais do que sobre suas formas ordinárias e concretas).

Como já havia ressaltado anteriormente, o objetivo de Connell é conhecer também como o moderno tem sido pensado no Sul. Até aqui nada seria muito diferente do que chamamos de pensamento social acadêmico em quase todas as partes do mundo (Maia, 2009). Segundo ela, porém, o dilema das teorias do norte é nunca terem se disposto para pensar com seus colegas do Sul. E mesmo quando estão abertas ao diálogo, exigem que este ocorra na língua e na forma tradicional, ou seja, colonial.

Deste dilema emergem os questionamentos: "podemos ter uma teoria social que não reivindique universalidade a partir de um ponto de vista da metrópole, que não observe de um único ponto de vista, que não exclua a experiência de pensamento social da maior parte da humanidade?" (Connel, 2007, p. 206).

Para aqueles acostumados em fazer sociologia no Sul, a reposta é óbvia e positiva. Por isso é interessante notar que Connell somente faz esse questionamento porque dedica a maior parte de seu livro a uma ampla revisão bibliográfica sobre algumas teorias para pensar o mundo moderno feita fora do eixo euro-americano. Este, do meu ponto de vista, é o grande mérito do livro e reflete um raro esforço de autores anglófilos de conceber um pensamento social mais democrático.

Em sua seção "olhando desde o Sul", temos leituras acuradas de debates pontuais produzidos em locais com os quais a autora parece ter estabelecido relações acadêmicas ao longo de sua vida. Esse também é um ponto importante, Connell respeita as teorias do $S u l$, porque manteve relações acadêmicas com diversos países fora da Euro-américa.

4 Para uma análise crítica e detalhada do modo de olhar de Bourdieu sobre a Argélia, ver a excelente coletânea organizada por Goodman e Silverstein (2009). 
Não é objetivo deste artigo discutir a leitura que Connell faz das sociologias que conheceu rodando pelo mundo, cujo critério de seleção é bastante claro e conscientemente limitado. Ainda que não possamos afirmar que o livro seja uma acurada ou mesmo justa revisão do pensamento social dos países ou regiões que ali aparecem, é importante ressaltar que a proposta de Connell difere das demais por não distinguir de antemão as sociedades do Sul e do Norte (como fazem Santos e Meneses e mesmo os Comaroff). Se para estes últimos as sociedades de Sul têm produzido formas de conhecimento alternativas às próprias ciências sociais, Connell prefere se referir ao problema do colonialismo dentro da própria sociologia e propõe uma relação simétrica como solução.

Ter sua pesquisa centrada nas relações de gênero implica uma vantagem, pois de certo modo, o tema do gênero sempre foi um Sul dentro da teoria sociológica, exigindo a construção de alternativas narrativas como buscaram fazer as epistemologias feministas (também citadas como exemplo no texto de Santos e Meneses).

Essa preocupação e perspectiva se refletem em uma distinta noção de grounded theory proposta para a teoria social que significaria uma "ligação entre a teoria e o lugar nas quais os pés dos teóricos estão plantados. Pensar desta maneira é rejeitar o arraigado hábito mental pelo qual as ciências sociais são admiradas exatamente pelo grau em que escapam de lugares específicos para falar de abstrações universais" (Connell, 2007, p. 206).

\section{Desafios e limites}

Como vimos, todas as três obras apontam para a necessidade de promover uma perspectiva do $S u l$, principalmente não colonial, no âmbito das ciências sociais. Cada uma a sua maneira e com seus métodos. Para Santos e Meneses, promover o Sul significa trazer outras formas de conhecimento, típicas ou genuínas destas regiões para o escopo de uma epistemologia geral, negativa e provisória que seja capaz de contribuir como solução para os dilemas cotidianos da vida contemporânea. Seu texto apela para uma convergência entre a ciência do Norte e outras formas de conhecimento típicas do Sul. Na tentativa de reforçar sua noção de pensamento abissal (típica do colonialismo), Boaventura de Sousa Santos prefere manter o dualismo como ponto de partida que lhe permite construir sua proposta de ecologia dos saberes. Quando confrontado com a leitura de Connell, o texto dos autores lusófonos presta pouca atenção ao fato de que no Sul também se produz ciência (social) e tira pouca vantagem do fato de ter em seu livro algumas figuras importantes do pensamento social latinoamericano e africano (em seu texto há apenas uma breve digressão sobre os dilemas de se constituir uma filosofia africana). Como anunciado também, nos 
demais capítulos escritos por outros autores, a ambição da obra é prestar mais atenção aos conhecimentos e formas de pensar subalternas e não intelectualmente hegemônicas do que em saídas científicas ou sociológicas. Podemos sugerir, portanto, que a obra de Boaventura de Sousa Santos é destinada a um público maior do que o das ciências sociais e não há como negar que haja um tom profético em sua proposta de uma nova forma de conhecimento.

Como já havia assinalado anteriormente, o apelo dos Comaroff por uma grounded theory esbarra na ausência de qualquer crítica, por sua parte, do conhecimento, das narrativas e dos vocabulários típicos das ciências sociais. ${ }^{5} \mathrm{~A}$ interessante constatação de que países do Sul estão lidando de maneira criativa com as mazelas do neoliberalismo e de que estas alternativas devam ser exploradas como theory from the South se revela limitada por uma compressão imperial do Sul. Do Sul como sendo apenas o objeto de ação e de reação aos processos sociais originados pela colonização do Sul como sendo o lugar do caos. Não há, por exemplo, um diálogo franco com as antropologias e sociologias feitas nesta parte do mundo, pois os autores assumem que sua forma e conteúdo não diferem daquelas feitas no norte. Em nome da unidade (evidentemente colonial) das ciências sociais parece haver um desleixo quanto à sua complexidade e uma obliteração dos desafios teóricos já enfrentados nas antropologias e sociologias locais que eventualmente poderiam significar algo originalmente formado no Sul.

Dilema da mesma ordem, mas de conteúdo distinto pode se encontrado no livro de Connell. Neste caso, é preciso considerar que Santos e Meneses fazem indiretamente um alerta importante para uma de suas lacunas. Não podemos acreditar que apenas porque estão sendo produzidos no Sul, certas teorias sociais não sejam também coloniais. A autora australiana não problematiza (ou melhor, problematiza apenas para o caso de seu próprio país) o fato de que muitas das ciências sociais são produzidas por elites coloniais ou por grupos locais mais interessados em se alinhar com as propostas de Giddens, Bourdieu e Beck, do que em fomentar desafios teóricos desenvolvidos endogenamente, ${ }^{6}$

5 Esta mesma característica aparece nos profícuos trabalhos de Domingues (2009 e 2009a), sobre a modernidade no Brasil e na América Latina. Nos trabalhos desse autor tem se privilegiado, por exemplo, uma crítica da noção de modernidade que prima pelo refinamento das matrizes clássicas do termo e não necessariamente pela crítica de sua pertinência como narrativa hegemônica neste campo de conhecimento.

6 Em um recente post em seu próprio website Connell comenta a experiência de participar do principal encontro de cientistas sociais do Brasil como conferencista e etnógrafa: "It really is a problem of hegemony - the usual assumption is that if you engage with Bauman, Bourdieu, Habermas and Foucault you are engaging with Theory, there is no sense that these guys represent specifically European experience". <www.raewynconnell.net/2011/11/with-socialsciences-in-brasil.html>. 
Ou seja, de trazer para o mesmo patamar o inevitável provincialismo euroamericano e os dos Sul.

Para ser um pouco mais acurado, o livro precisaria levar em conta uma espécie de colonialismo interno das ciências sociais nas quais os teóricos e pesquisadores locais em geral impõem agendas de pesquisa alienígenas em seus próprios países (os usos e abusos dos chamados barômetros que medem a democracia ou dos graus e fases da modernidade seriam um bom exemplo). Não podemos esquecer que a maioria dos cientistas sociais do Sul tem pouco ou nenhum contato com as formas locais ou endógenas de conhecimento do social. Também não podemos ignorar que muitos dos teóricos baseados no Sul, pela própria ordem colonizadora da disciplina, estão de fato com seus pés não na terra onde escrevem, mas sim nas narrativas abstratas globais. Como nos adverte Nyamnjoh (2012), por vezes nossos teóricos parecem mais "mudas de estufa" (potted plants in Greenhouses) cujo ambiente é tão puro e ideal quanto as narrativas sobre modernidade que recebemos e ensinamos em nossos cursos nas universidades do Sul. Nem toda teoria feita no Sul é, portanto, grounded theory. ${ }^{7}$

Apenas Boaventura de Sousa Santos, mesmo que de forma superficial, leva em consideração o fato de as ciências sociais e suas narrativas serem produzidas localmente por elites intelectuais que, mormente, são também elites políticas e econômicas. Diferentemente dos debates endógenos da África e da Índia, é preciso reconhecer que na América Latina, na Austrália e talvez no Irã aqueles que produzem teoria sobre o mundo moderno, são colonizadores, se consideram modernos e têm pouca ligação ou admiração por outras epistemologias de que falam Santos e Meneses. Ao cabo, seriam estratos sociais que não dialogam mais profundamente com a maioria das populações de seus países - às vezes por considerá-los apenas como parte de uma classe objeto. São grupos que podem simplesmente não enxergar as descontinuidades (Connell, 2007, p. 45) e, na busca de legibilidade internacional e local, procuram se inserir nas grandes e simplistas narrativas pré-moderno/moderno ou pré-capitalista/capitalista.

\section{Sobre as noções de Sul e de teoria: grandezas em formação}

A hipótese central desta análise da literatura é de que a noção de $S u l$ e sua extrema variação de obra para obra está ligada aos diferentes sentidos e

\footnotetext{
7 Um contraponto teoricamente clássico, e talvez contemporaneamente hegemônico na sociologia latino-americana, é presentado por autores como Mascareño e Chernilo (2009). Neste artigo, os autores defendem ancorados em conceitos luhmanianos a necessidade que as teorias da região se tornem abstratas o suficiente para saírem de suas armadilhas políticas e históricas.
} 
valores que se atribui ao termo teoria em cada um dos casos. Do meu ponto de vista, para quem analisa estas obras desde o $S u l$, o entusiasmo inicial vendido pelos títulos não se converte propriamente em elementos que configurem uma alternativa per se. Há pelo menos dois pontos centrais que demonstram que o $\mathrm{Sul}$ ainda é um rótulo menos homogêneo que o "pós-colonial" ou o "decolonial" e que não teria estabelecido ainda, na palavras de Boltanski e Thévenot (1991), uma convenção de grandezas e princípios de equivalência capazes de possibilitar reconhecimentos mútuos entre as diversas iniciativas apresentadas (ao contrário das teorias da modernidade, por exemplo).

A primeira constatação é de que a própria ideia do que é teoria é muito diferente em cada caso. Para Santos teoria é epistemologia, para os Comaroff teoria é prática, e para Connelll teoria é pensamento social acadêmico. Assim, a unidade encontrada nos títulos sucumbe a universos analíticos bastante diversos, cujas grandezas (no sentido atribuído por Boltanski, 2000) correspondem a disputas por coisas diferentes. Mesmo que constatemos, de forma otimista, que o conjunto dos textos pode representar um movimento inovador nas ciências sociais, as provas e objetos lançados ao debate não são equivalentes. Nas formas de conhecimento que seriam típicas do Sul vemos a valorização de competências (conhecimentos não científicos, conhecimentos práticos ou sociologias locais) que, sendo muito díspares, levam a própria sociologia para caminhos nem sempre conciliáveis em termos metodológicos. Essas competências também são atribuídas a sujeitos distintos como indígenas, trabalhadores informais ou cientistas sociais.

A segunda diz respeito ao fato de quando postos lado a lado, os trabalhos não permitirem uma definição clara do que seria o Sul como matriz de conhecimento para as ciências sociais. Nesse sentido, não haveria diferença significativa entre as sociologias do $\mathrm{Sul}$ e as sociologias pós-coloniais, pois ambas defendem como unidade analítica os efeitos do colonialismo, mais do que uma concreta homologia entre as formas da vida nesses diversos lugares. As sociologias do Sul (no Irã, na Nigéria, na Austrália, na Índia e na América Latina), citadas por Connell, por exemplo, não dialogam entre si. Elas são, na maioria dos casos, construções nacionais e, em muitos casos, nacionalistas ${ }^{8}$ (crítica que também poderia ser feita obviamente para uma parte significativa da teoria social euro-americana, como no livro de Chakrabarty, 2000). O melhor exemplo disso é a África como apresentada pelos Comaroff: um apanhado generalizante de informações de segunda mão que, de maneira 8 Para uma análise mais específica das narrativas sociológicas nacionais e nacionalistas, no
âmbito teórico, ver Ortiz (2012), Maia (2009 e 2011) e Chernilo (2006). 
forçada e pouco precisa, aparecem ao lado de questões pontuais como, por exemplo, o bolsa família no Brasil (Comaroff e Comaroff, 2011, p. 44). Na mesma linha generalista (ao melhor estilo da teoria tradicional criticada por Connell), os conhecimentos não científicos de Santos abrangem desde a prática de cultivo de arroz na Ásia aos sem-terras, indígenas e quilombolas também do Brasil (Santos, 2009, p. 50), grupos que, ao contrário do que sugere o autor, em suas lutas cotidianas apresentam diferenças epistemológicas abissais e por vezes antagônicas como aponta Rosa (2012).

Do ponto de vista das disputas e das grandezas acionadas, a forma como Sul e teoria estão presentes em cada um dos textos analisados torna praticamente impossível reuni-los de maneira estável e permanente. Em termos da opção teórico-metodológica desta análise (na qual a questão central é a disputa), o Sul poderia ser considerado uma grandeza (uma prova de valor) ainda estrangeira ao universo sociológico e para a qual ainda não há uma estabilização de elementos que lhe atribuam um lugar específico para ser avaliado. Em minha leitura, tal característica está ancorada justamente no fato de que nos três livros (mas especialmente na contribuições de Comaroff e Comaroff e de Connell), há um claro desconforto com os sentidos, as noções e os usos das teorias dominantes na ciências sociais. $\mathrm{O}$ estranhamento da teoria em sua forma hegemônica não permite assim que o Sul seja simplesmente localizado dentro de um campo ou que a ele seja atribuído um dos clássicos papéis do pensamento crítico, como, por exemplo, o de periferia. Percebo nesses textos justamente um chamamento à necessidade de se transformar tanto os cenários, quando os papéis possíveis para a sociologia.

Retomando outra característica central do modelo da "economies de la grandeur" de Boltanski e seus parceiros, os desafios e as grandezas propostas pelas três obras poderiam ser interpretados como críticas, no sentido desenvolvido em O novo espírito do capitalismo (Boltanski e Chiapello, 2002, p. 73). Ao expor com ênfase algumas das fraquezas e das falácias da teoria social hegemônica, eles tendem a obrigar o conhecimento estabilizado a se justificar - por algumas das injustiças que comete ou cometeu, sendo as respostas adequadas a alguns destes questionamentos condição essencial para que a própria disciplina (assim como o capitalismo, no caso de Boltanski e Chiapello) continue a existir em um contexto cada vez mais crítico.

\section{Considerações finais: o $S u l$ como projeto crítico}

A revisão dessas três obras teve como objetivo compreender sob quais condições o conceito de Sul tem sido utilizado para fomentar o debate sobre a produção sociológica fora da Euro-américa em textos recentes. No passado 
e em outras circunstâncias, vários autores como Alatas (2006), Sosa (2006) e Sitas (2006) utilizaram o adjetivo Sul para se referir de forma genérica à produção acadêmica fora da Euro-américa. No entanto, estes e outros autores lançaram mão do termo de forma ampla sem se ocuparem em buscar uma definição mais precisa capaz de torná-lo mais instrumental nas disputas sociológicas. É esta busca por um uso mais acurado do termo nas atuais condições geopolíticas que me parece diferenciar a literatura aqui analisada.

Em se tratando de uma disputa por legitimidade (política e teórica), não podemos deixar de lado considerações sobre o fato de essas novas lentes serem homologáveis ou não para sua participação no debate. Nas teorias da dependência, das modernidades múltiplas, do pós e do decolonialismo, as construções partem de fatos que tendem a aparecer como auto evidentes para qualquer cientista social tradicional. Poucos teriam coragem de duvidar da existência da modernidade e também de sua face colonial, já que encontramos (e somos treinados para isso) seus traços e efeitos em muitos lugares do globo. Sobre o Sul, no entanto, pairam muitas dúvidas, não sabemos exatamente quais são seus efeitos e tampouco como identificar seus rastros, suas bordas e fronteiras.

De forma geral me parece que seria possível resumir o esforço dos trabalhos aqui apresentados como uma tentativa de fazer existir (to enact, na versão de John Law, 2004) o Sul. O fazer dessa existência (to enact) depende intrinsecamente da produção de características e de métodos de deteç̧ão que estão em curso e em processo de legitimação. Se tomados em conjunto, como neste texto, fica evidente que não há nessas obras uma uniformidade que nos permita usá-lo, sem titubear, qual uma ferramenta, ao modo como se fez em outras tradições mencionadas ao longo do texto. Os traços dos Sul estão dispersos em teorias da prática, em práticas não científicas e em sociologias locais. Tanto em uma leitura tradicional quanto retomando a noção de economies de la grandeur, os argumentos aqui explorados não revelam ainda um princípio superior capaz de reorganizar as disputas teóricas hegemônicas (Boltanski e Thévenot, 1991, p. 54-56); quem sabe talvez sequer pretendam chegar a esse ponto.

Ainda dentro do esquema proposto por Boltanski e Thévenot (1991), a pergunta que fica aos leitores diz respeito a como considerar a literatura sobre o $\mathrm{Sul}$ de forma legítima. Em certa medida poderíamos pensar que o $\mathrm{Sul}$, no sentido aqui exposto, é um projeto, a exemplo daqueles descritos por Boltanski e Chiapelo (2002), que faz parte de um "novo espirito" no qual se desenvolve a ciência social contemporânea. Esse novo espírito teria por característica, pensando nos três textos aqui apresentados, ser composto por 
uma multiplicação de encontros e conexões temporárias, porém reativáveis, com grupos diversos, realizadas eventualmente a distâncias sociais, profissionais, geográficas e culturais muito elevadas. O projeto é a ocasião e o pretexto para a conexão, reunindo temporariamente a pessoas muito díspares se apresentado como um extremo fortemente ativado da rede durante um período curto de tempo [...] (Boltanski e Chiapello, 2005, p. 104).

O extremo fortemente ativado, neste caso, é a necessidade de trazer os processos sociais vividos fora da Euro-américa para o centro da teoria social de forma qualificada, simétrica e não apenas como contra exemplos ou derivações da grande marcha para o ocidente.

\section{Referências}

ALATAS, S. F. A Khaldunian exemplar for a historical sociology from the South. Current Sociology, v. 54, n. 3, p. 397-411, 2006.

BOLTANSKI, L. El amor y la justicia como competencias. Buenos Aires: Amorrutu, 2000.

BOLTANSKI, L.; CHIAPELLO E. The new spirit of capitalism. London: Verso, 2005. BOLTANSKI, L.; THÉVENOT L. De la justification. Paris: Galimard, 1991.

BORGES, A. Explorando a noção de etnografia popular: comparações e transformações a partir dos casos das cidades-satélites brasileiras e das townships sul-africanas. Cuadernos de Antropología Social, v. 29, p. 23-42, 2009.

BURAWOY, M.; CHANG, M.; HSIEH, M. F. Facing an unequal world: challenges for a global sociology. Volume one: introduction, Latin America and África. Taiwan: Institute of Sociology, Academia Sinica, Council of National Associations of the International Sociological Association, Academia Sinica, 2010.

CHAKRABARTY, D. Provincializing Europe: post colonial tough and historical difference. Princeton: Princeton University Press, 2000.

CHERNILO, D. Social theory's methodological nationalism. European Journal of Social Theory, v. 9, n. 1, p. 5-22, 2006.

COMAROFF, J. Teorias do sul. Mana, v. 17, n. 2, p. 467-480, 2011.

COMAROFF, Jean; COMAROFF, John. Theory from the South: or how Euro-America is evolving toward Africa. London: Paradigm Publishers, 2011.

CONNELL, R. Southern theory: the global dynamics of knowledge in social science. Cambridge: Polity, 2007.

DOMINGUES, J. M. A América Latina e a modernidade contemporânea: uma interpretação sociológica. Belo Horizonte: Editora UFMG, 2009a.

DOMINGUES, J. M. Global modernization, 'coloniality', and a critical sociology for contemporary Latin America. Theory, Culture and Society, v. 26, n. 1, p. 112-133, 2009. 
EISENSTADT, S. Multiple modernities. Daedalus, v. 129, n. 1, p. 1-28, 2000.

FABIAN J., Time and the other: how anthropology makes its objects. New York: Columbia University Press, 2000[1983].

GO, J. For a postcolonial sociology. Theory and Society, v. 42, n. 1, p. 25-55, 2013.

GOODMAN, J.; SILVERSTEIN, P. A. (Orgs.). Bourdieu in Algeria: colonial politics, ethnographic practices, theoretical developments. Lincoln: University of Nebraska Press, 2009.

GROSFOGUEL, R. Descolonizar as esquerdas ocidentalizadas: para além das esquerdas eurocêntricas rumo a uma esquerda transmoderna descolonial. Contemporânea, v. 2, n. 2, p. 337-362, 2012.

HOUNTONDJI, P. J. Endogenous knowledge: research trails. Dakar: Codesria, 1997.

LAW, J. After method: mess in social science research. New Yourk: Routledge, 2004.

MAFEJE, A. Africanity: a combative ontology. Codesria Bulletin, v. 1, p. 66-71, 2000.

MAIA, J. M. Ao Sul da teoria: a atualidade teórica do pensamento social brasileiro. Sociedade e Estado, v. 26, p. 71-94, 2011.

MAIA, J. M. Pensamento brasileiro e teoria social: notas para uma agenda de pesquisa. Revista Brasileira de Ciências Sociais, v. 24, p. 155-168, 2009.

MASCAREÑO, A.; CHERNILO, D. Obstacles and perspectives of Latin American sociology: normative universalism and functional diferentiation. Soziale Systeme, v. 15, n. 1, p. 72-96, 2009.

MIGNOLO, W. Epistemic disobedience, independent thought and decolonial freedom. Theory, Culture \& Society, v. 26, n. 7-8, p. 159-181, 2009.

MIGNOLO, W. Local histories/global designs: coloniality, subaltern knowledges, and border thinking. Princeton: Princeton University Press, 2000.

NYAMNJOH, F. 'Potted plants in greenhouses': a critical reflection on the resilience of colonial education in Africa. Journal of Asian and African Studies, v. 47, n. 2 , p. 129-154, 2012.

ORTIZ, R. As ciências sociais e a diversidade dos sotaques. Revista Brasileira de Ciências Sociais, v. 27, n. 78, p. 7-24, 2012.

ORTNER, S. B. Specifying agency: the Comaroffs and their critics. Interventions: international journal of postcolonial studies, v. 3, n. 1, p. 76-84, 2001.

PATEL, S. The ISA handbook of diverse sociological traditions. London: Sage, 2010.

ROSA, Marcelo C. Reforma agrária e land reform: movimentos sociais e o sentido de ser um sem-terra no Brasil e na África do Sul. Caderno CRH, v. 25, p. 99-114, 2012.

SANTOS, B. de S. Para além do pensamento abissal: das linhas globais a um ecologia dos saberes. In: Boaventura de Sousa Santos; Maria Paula Meneses (Orgs.). Epistemologias do Sul. Coimbra: Almedina-CES, 2009. p. 23-73.

SANTOS, B. de S.; MENESES, M. P. Epistemologias do Sul. Coimbra, AlmedinaCES, 2009. 
SITAS, A. The African renaissance challenge and sociological reclamations in the South. Current Sociology, v. 54, n. 6, p. 357-380, 2006.

SOSA, R. Sociology and the South: the Latin American experience. Current Sociology, v. 54, n. 3, p. 413-425, 2006.

Recebido em: 15 jul. 2013

Aprovado em: 25 nov. 2013

Autor correspondente:

Marcelo Rosa

Campus Darcy Ribeiro, Departamento de Sociologia, UnB

70910-900 Brasília, DF 